\title{
А.В. Грицюк
}

\section{СОЗДАНИЕ ЭКСПЕРИМЕНТАЛЬНОЙ БАЗЫ ХАРЬКОВСКОГО КОНСТРУКТОРСКОГО БЮРО ПО ДВИГАТЕЛЕСТРОЕНИЮ}

\begin{abstract}
Представлена документальная информащия по истории создания экспериментальной базы Государственного предприятия «Харьковское конструкторское бюро по двигателестроению» (ХКБД). Показана первостепенная роль испьтательного оборудования экспериментальной базы в обеспечении эффективной работы исследовательского направления КБ. Отмечен вклад каждого из руководителей исследовательского направления в сохранение и приумножение научно-технического потенциала ХКБД. Посвящается 50-летнему юбилею имени «ХКБД».
\end{abstract}

Далеко не часто в истории предприятий двигателестроения Украины случаются торжественные события. Таким событием в текущем году должен и вполне мог бы стать 50 - летний юбилей теперешнего Государственного предприятия «Харьковское конструкторское бюро по двигателестроению» (ХКБД).

В своей публикации [1] автор этой статьи дал обещание установить дату рождения имени одного из передовых дизельных КБ Советского Союза, а в последующем Украины. Именно этому событию выпала незаслуженная участь быть искаженным в нескольких историко-технических публикациях $[2,3]$, что в определенной степени затруднило поиск истины. Нет особой необходимости рассказывать читателю о кропотливой работе с архивами. Пришлось ознакомиться с документами во всех подразделениях ХКБД, Завода им. В.А. Малышева и Национального архивного фонда, чтобы в Государственном архиве Харьковской области найти и за истечением давности лет рассекретить некогда совершенно секретный приказ Министра оборонной промышленности СССР №110 от 06.03.1966 года. Скан-копии первого листа приказа и выписки из приложения №1 к этому приказу (приведены по тексту) поставили окончательную точку в «белом пятне» истории ХКБД, и произошло это в ноябре 2015 года, т.е. за четыре месяца до исторического события, с передачей всех материалов в ГК «Укроборонпром». Но имеем то, что имеем, 6 марта 2016 - дата 50-летия имени некогда прославленного КБ прошла незаметно.

Возвращаясь к теме статьи и осознавая, что не замечается только то, что очень хочется не заметить, хотелось бы отметить основное. Наряду со становлением коллектива талантливых конструкторов, исследователей и технологов, развиваться, крепнуть и создавать конструкции, опережающие время [4,5], ХКБД помогли совпавшее со временем рождением имени представившиеся последующие возможности в прекрасном оснащении исследовательских подразделений экспериментальной базой.
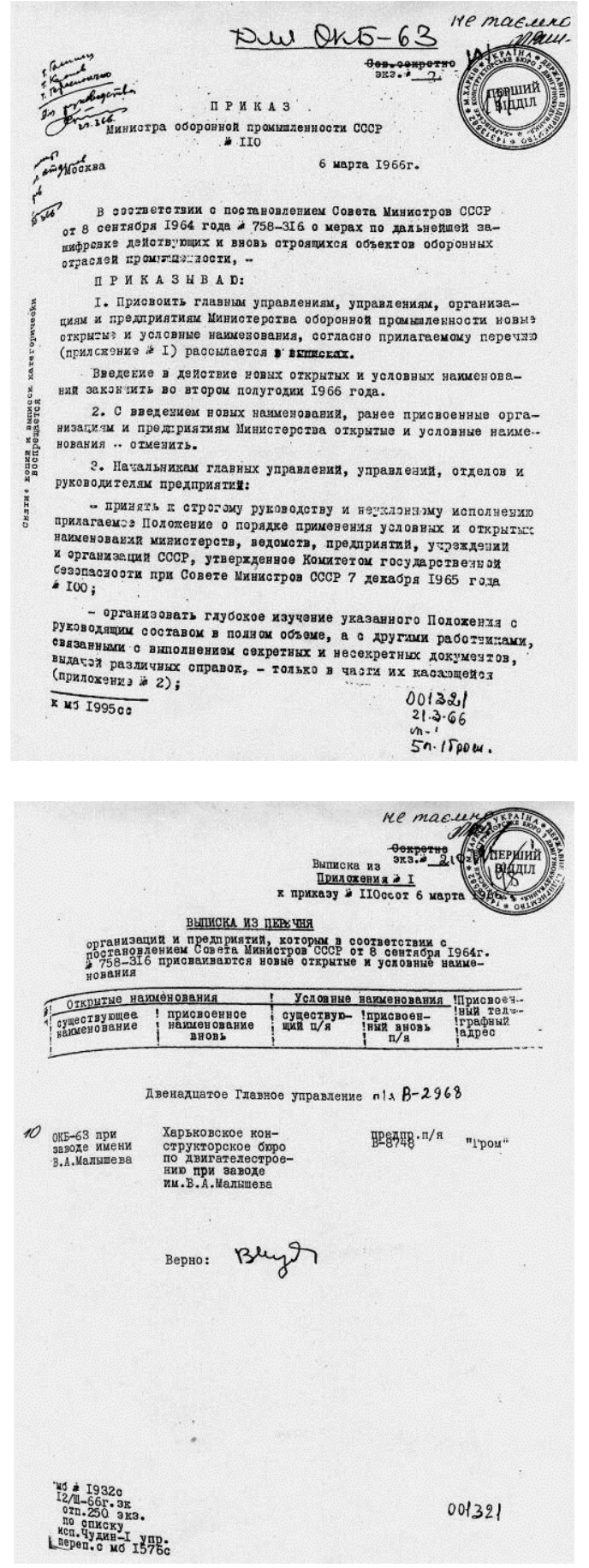
Имея более чем 42-х летний трудовой стаж и непрерывный контакт с экспериментальной базой ХКБД, хочется, как можно более объективно, осветить её историю с момента рождения и до сегодняшнего дня, т.е. её реальное состояние на 01 июля 2016 года.

Моментом рождения экспериментальной базы ГП «ХКБД» по праву можно считать приказ Министра оборонной промышленности СССР от 29 августа 1967 года №314 и последовавший за ним приказ директора завода транспортного машиностроения им. В.А. Малышева Олега Владиславовича Соича от 8 сентября 1967 года №382. Согласно сканкопии первого листа приказа Министра (приведена по тексту) экспериментальная база ХКБД сосредоточилась в испытательных боксах и в боксах №9, $10,18,20$ и 21 корпуса серийного производства «1000» (в последующем «300С») и в боксах №1 (многотопливный стенд) и №3 (стенд МТО) корпуса «181С». Строительно-монтажные работы по вводу в строй экспериментальной базы велись с 1967 по 1969 год.

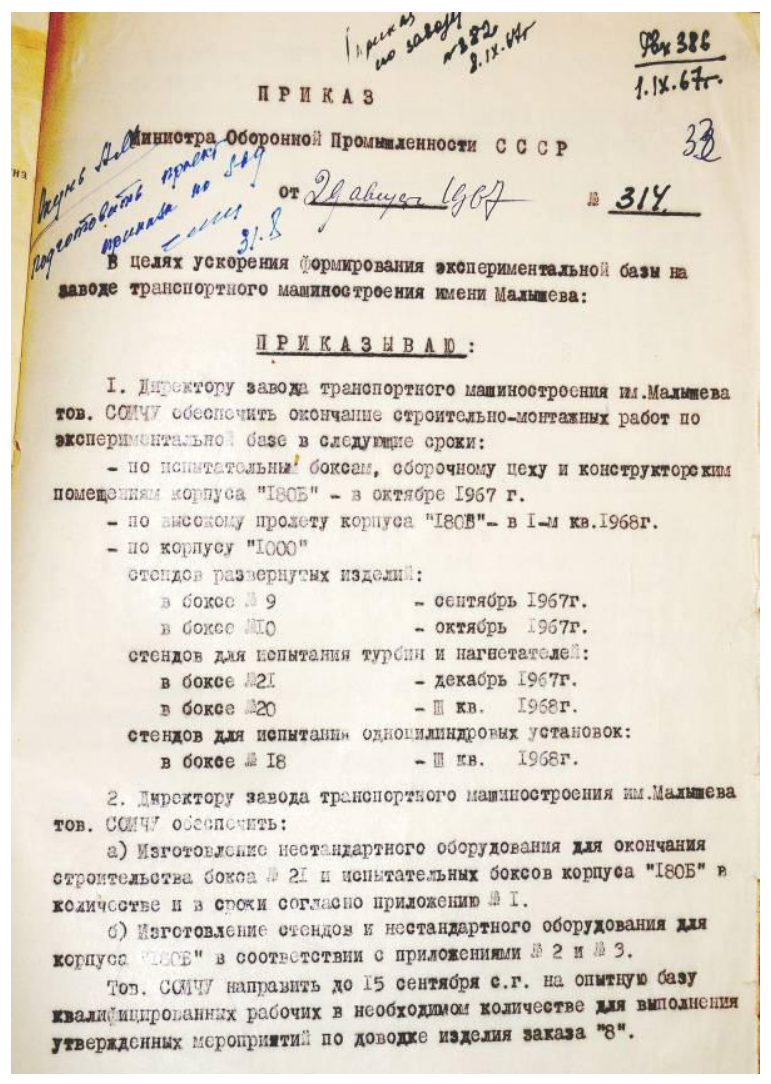

Экспериментальная база вводится в состав и становится фундаментом исследовательского направления конструкторского бюро. Исследовательское направление возглавляет заместитель главного, а в последующем генерального, конструктора по научно-исследовательской работе. За 50-летнюю историю ХКБД их было четыре. Все они выпускники Харьковского политехнического института (в последующем НТУ «ХПИ»). Два кандидата и один доктор технических наук.

Первым заместителем главного конструктора по научно-исследовательской работе был Пашкин Олег Леонидович, назначенный на эту должность 18 апреля 1966 года. О.Л. Пашкин возглавлял исследовательское направление с 1966 по 1969 гг. За этот период в эксплуатацию было введено 48 единиц опытного оборудования. Именно О.Л. Пашкину досталась тяжёлая участь закладки фундамента и возведение поистине «каменных стен» экспериментальной базы ХКБД. Позже он был назначен главным инженером и до выхода на заслуженный отдых возглавлял производственное направление.

После О.Л. Пашкина заместителями главного конструктора по научно-исследовательской работе назначались исключительно кандидаты технических наук, знающие цену экспериментальным исследованиям для познания сути, возникающих в двигателе проблем.

10 февраля 1969 года заместителем главного конструктора по НИР назначен Власенко Игорь Павлович. Он возглавлял направление во времена доводки двигателя 5ТДФ на фоне общего стремительного роста производства отечественных ДВС. С целью ускорения доводки двигателя 5ТДФ, при прочих благоприятных условиях, под руководством И.П. Власенко создано около 50-ти методик ускоренных испытаний отдельных узлов и двигателя в целом, что позволяло в 5 - 10 раз сократить время воспроизведения дефекта и быстро отработать мероприятия по его устранению. Реализация этих методик потребовала разработки, изготовления и ввода в эксплуатацию значительного количества нестандартного и покупного оборудования для модернизации существующих и изготовления новых стендов. Создаётся новый сектор по разработке оригинального испытательного оборудования, экспериментальная база усиливается двумя мобильными переносными стендами для отработки конструктивных мероприятий по обеспечению пуска двигателя 5ТДФ, а под его длительные испытания вводятся в строй моторные стенды в боксах №16 и 17 серийного корпуса "1000". В боксе №19 того же корпуса прописывается исследовательский островок одноцилиндровых отсеков танкового дизеля.

Игорь Павлович значительно усиливает работу по профессиональной подготовке кадрового состава исследователей и повышению их квалификации. В период его руководства сотрудниками КБ без отрыва от производства защищается семь кандидатских диссертаций. Одну из них защищает 
Ю.С. Бородин, который и становится приемником И.П. Власенко.

Бородин Юрий Семёнович принимает «эстафетную палочку» заместителя главного конструктора по НИР 9 сентября 1985 года - в «жаркую пору» постановки на производство танкового дизеля 6ТД-1 [3]. Необходимость освоения в кратчайшие сроки танкового двигателя мощностью 1000 л.с., при существующем жёстком графике изготовления серийного дизеля 5ТДФ, потребовала максимального подключения производственной и экспериментальной баз ХКБД к освоению выпуска нового двигателя. Автор данной статьи на примере личного участия в процессе внедрения в серийное производство в 2010 - 2013 гг. дизеля 3ТД-3А для бронированной машины БТР-4Е не понаслышке знает, какую огромную роль в таких процессах играют исследовательские подразделения ХКБД. От входного контроля новых комплектующих до проведения обкаточных, регулировочных и приёмосдаточных испытаний вновь изготавливаемых узлов и дизеля в целом.

Вплоть до 2000 года параллельно сопровождению серийного производства идёт разработка танкового дизеля третьего поколения [4], под испытания опытных образцов которого не единожды переделывается стендовое оборудование в боксе №9 корпуса 300C агрегатного завода. Под аналогичные цели обеспечения пуска дизеля со сверхнизкой степенью сжатия разрабатывается и изготавливается третий перекатный стенд.

В период руководства НИР Бородиным Ю.С. защищает докторскую диссертацию Генеральный конструктор Николай Карпович Рязанцев, а работающая семья кандидатов технических наук вырастает ещё на 9 человек. Юрием Семёновичем протаптывается дорога в реестр научных организаций Украины, которая сопровождается ежегодной подготовки статей во Всеукраинский научнотехнический журнал «Двигатели внутреннего сгорания» с последующим участием в работах Международных конгрессов двигателестроителей в Украине.

В 1990 году кандидатом технических наук становится и автор этой статьи, возглавивший исследовательское направление 30 апреля 2004 года. При этом в условиях уже просматривающегося дефицита высококвалифицированных универсальных кадров Грицюк А.В. остался руководителем работ по малолитражным двигателям [5], усилив исследовательское направление двумя конструкторскими подразделениями. Новые неординарные решения были продиктованы «украинскими реалиями» отсутствия потребности в создании двигателей для бронетанковой техники. Разрабатывать нужно было уже не то, что соответствует специа- лизации ХКБД, а то, что необходимо, и может отвечать мировому уровню, и чем можно в последствии гордиться. При этом на выживание необходимы финансовые ресурсы.

Как в такой ситуации работать предприятиям, которые ранее никогда самовольно круг своих задач не определяли? Входя в государственный реестр научных организаций, которым предоставляется государственная поддержка, ХКБД в отличие от академической и вузовской науки, которых опекали государственные ведомства, оказалось один на один с отечественным законодательством, работая в том же режиме, что и промышленные, а даже торговые предприятия. В этих условиях экспериментальная база, сохраняя и развивая имеющийся научно-технический потенциал, занималась всем: выполнением международных научно-технических проектов НТЦУ, разработкой и реализацией Государственной программы развития производства отечественных малолитражных дизелей, инновационными и инвестиционными проектами, Государственным оборонным заказом. Девять комплектов конструкторской документации изделий, разработанных исследовательским направлением, получили литеру «О», а семь из них доведены до высшей литеры процесса разработки - «О 1 ». Этому успеху способствовала разработка и введение в строй пяти стендов: для малолитражных двигателей в одно-, двух-, трех-, и четырехцилиндровом исполнении; электроагрегатов; энергоагрегатов и жидкостных нагревателей проточного типа. Три введенных в эксплуатацию стенда приняты комиссией и в 2015 году введены в основные средства предприятия, достойно пополнив арсенал экспериментальной базы. Стенды были расположены в просторном боксе №5 корпуса «181C».

Экзамен состоятельности принятой стратегии выживания экспериментальная база успешно сдала в 2010-2013 годах, сделав эффективный, и можно сказать определяющий, вклад в уже упомянутый процесс постановки на серийное производство дизеля 3ТД-3А.

Топливная система высокого давления, регулятор, гаситель крутильных колебаний, маховик, входной контроль всех электротехнических изделий, обкатка и регулировка компрессора и турбины, обкатка и приемо-сдаточные испытания дизеля в целом - вот далеко не полный перечень задач, решаемых серийным производством агрегатного завода с помощью экспериментальной базы ГП «ХКБД». При этом под испытания дизеля 3ТД-3А модернизируется стенд в боксе №17 корпуса «300С» и создаётся новый стенд в боксе №4 корпуса «181С».

На фотографиях рис. 1-4, сделанных 12 мая 2016 года, запечатлены фрагменты и фирменная 
табличка оборудования стенда прочностных испытаний в процессе проведения, до настоящего времени закрепленной за ХКБД, работы по разгону крыльчатки серийного компрессора дизеля 6ТД-2Е.

Данный стенд введен в строй вышеприведенными приказами 1967 года (№214 и №382) и бла-

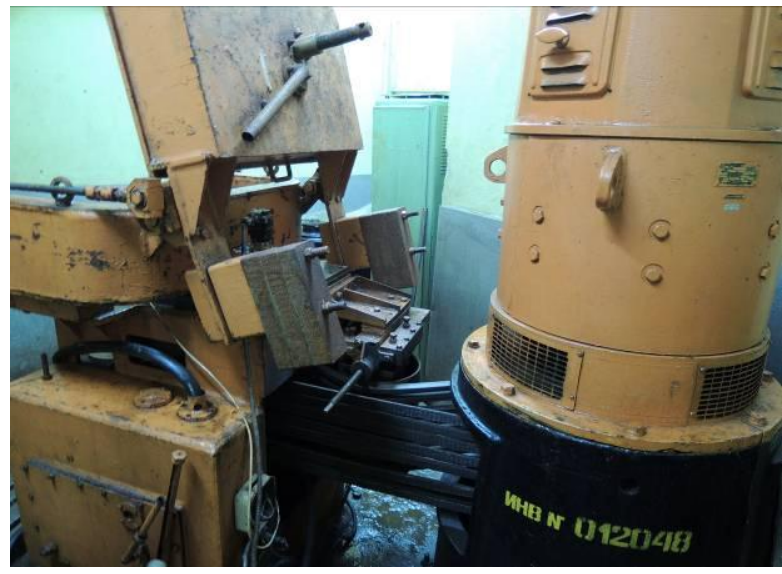

Рис. 1. Общиий вид стенда для разгонныхх испытаний

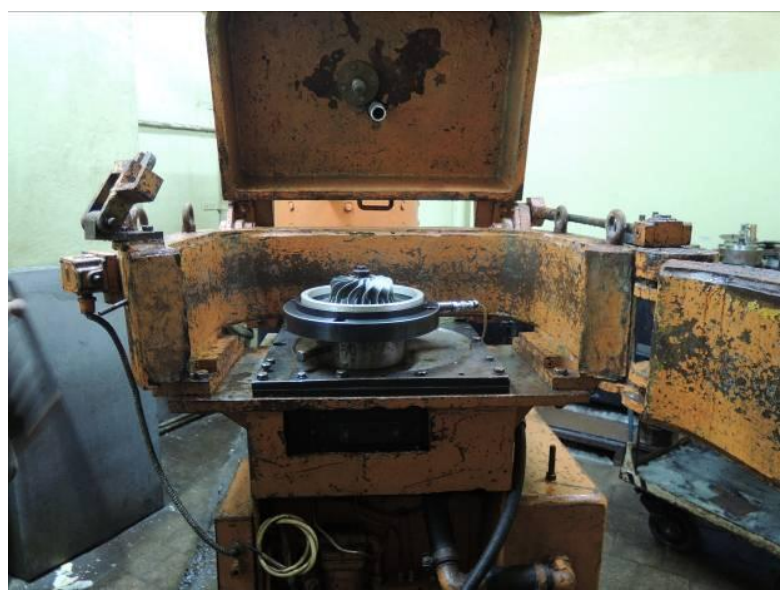

Рис. 3. Стенд для разгона крыльчатки компрессора дизеля 6ТД-2Е

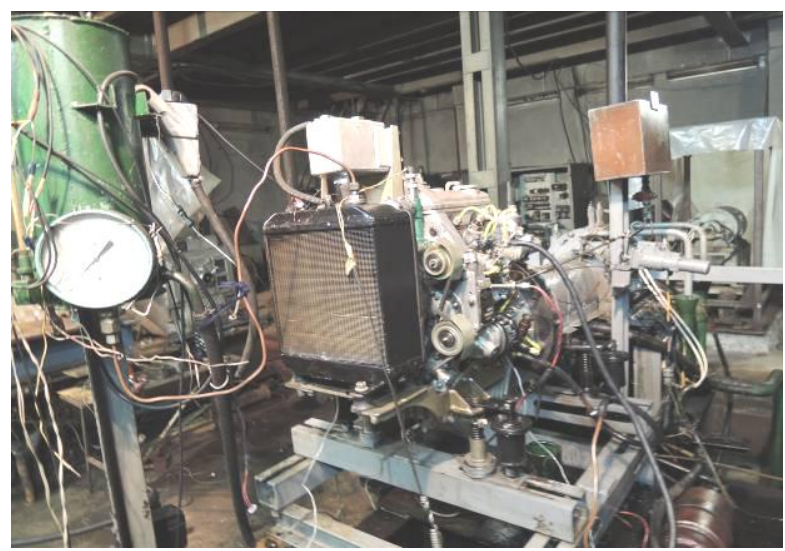

Рис. 5. Общчий вид стенда Ст655Сб для испьттаний малолитражных дизелей серий 1ДТА и 2ДТА гополучно эксплуатируется до настоящего времени наряду с современным приобретением экспериментальной базы - стендом Ст655Сб (рис. 5 и 6), на котором в настоящее время проводят обкаточные и приёмо-сдаточные испытания дизелей 2ДТАЭ Оборонного заказа.

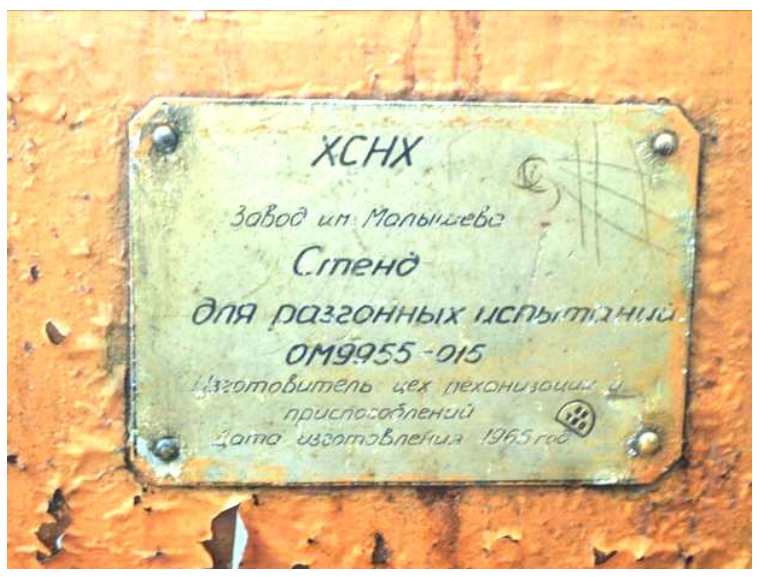

Рис. 2. Фирменная табличка стенда для разгонньхх испьтаний

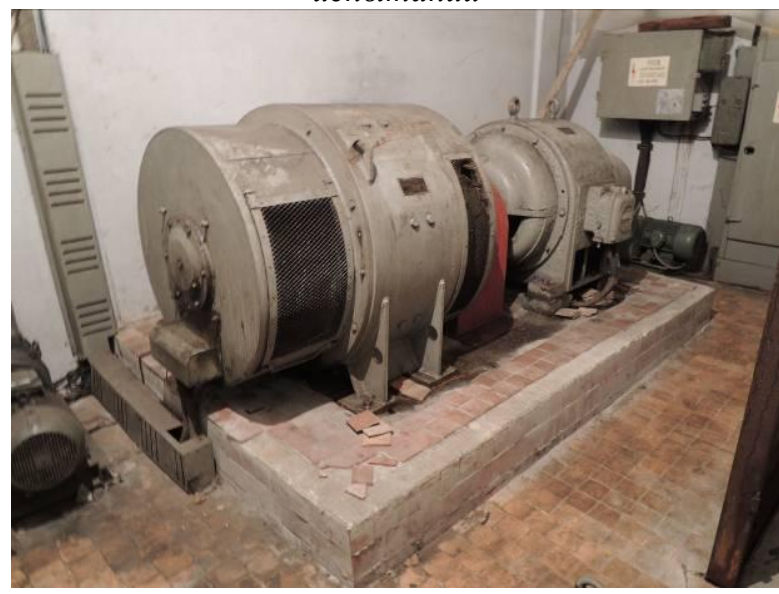

Рис. 4. Двухмашинный агрегат электропитания стенда для разгонных испытаний

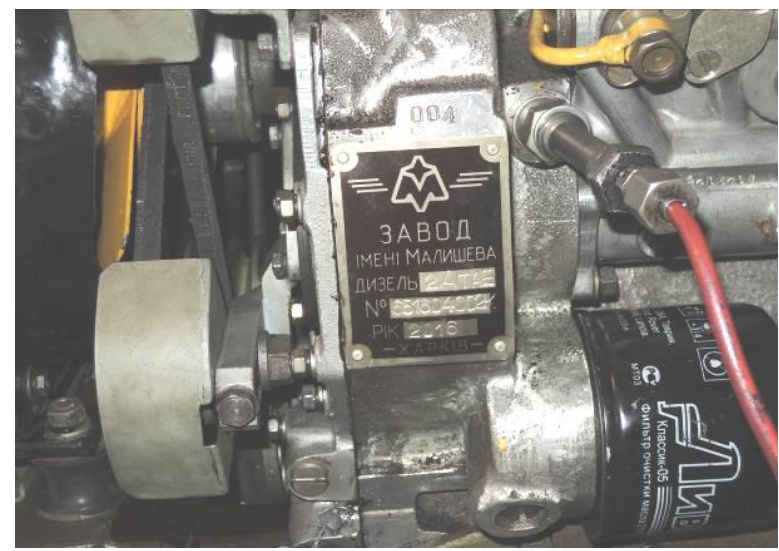

Рис. 6. Дизель 2ДТАЭ на стенде Ст655Сб при проведении приёмо-сдаточных испытаний в июне 2016 года 
С 2004 года восстановилась, прерванная после распада СССР, подготовка и защита диссертаций сотрудниками ХКБД. На 01 июля 2016 года защищены без отрыва от производства одна докторская и три кандидатских диссертации. Впервые в истории ученые ХКБД стали участниками престижных всемирных конференций в области дизелестроения [1].

Таким образом, создание мощной экспериментальной базы с основательным испытательным оборудованием сделали исследовательское направление наиболее значимой и неуязвимой частью сложнейшего организма по имени «Харьковское конструкторское бюро по двигателестроению». И сегодня, когда возвращается заинтересованность государства к продукции оборонного комплекса, экспериментальная база ХКБД способна организовать тот направленный поток воздушного заряда, который, используя сохранённый и вновь созданный научно-технический потенциалы, надует паруса и поведёт к новым горизонтам некогда всемогущее КБ по двигателестроению.

\section{Список литературы:}

1. Грииюк А.В. Выпускники ТМ факультета Харьковского Политеха в Харьковском конструкторском бюро по двигателестроению / А.В. Грииюк // Двигатели внутреннего сгорания. - 2015. - № 1. - С. 85-89. 2. История двигателестроения на ХПЗ - Заводе имени Мальшева 1911 2001 г.г.: Историко-технические очерки о двигателях и их создателях / А.В. Быстриченко, Е.И. Добровольский, А.П. Дроботенко и др.; под. ред. к.т.н. М.М. Будённого. Харьков: «Митеиь», ГП «Завод им. Мальшева», 2001. 480 c. 3. Рязанцев Н.К. Моторы и судьбы. О времени и о себе: Воспоминания Генерального конструктора по созданию двигателей для бронетанковой техники / Н.К. Рязанцев. - Харьков: ХНАДУ, 2009. - 272 с. 4. Алёхин С.А. Опередившие время / С.А. Алёхин, А.В. Грииюк // Двигатели внутреннего сгорания. - 2011. №1. С.25-28. 5. Грииюк А.В. Новое направление в дизелестроении Украины/ А.В. Грииюк, И.В. Парсаданов, А.А. Мотора // Двигатели внутреннего сгорания. - 2011. - № 1. - C. 48-53.

\section{Bibliography (transliterated):}

1. Gritsyuk A.V.(2015), The graduates of Transport Mechanical engineering faculty at Kharkiv Polytechnic Institute in the Kharkiv engine design bureau [Vypuskniki TM fakul'teta Khar'kovskogo Politekha $v$ Khar'kovskom konstruktorskom byuro po dvigatelestroeniyu], Dvigateli vnutrennego sgoraniya. no1. pp. 85-89. 2. Bystrichenko A.V., Dobrovol'skii E.I., Drobotenko A.P. i dr.; pod. red. k.t.n. Budennogo M.M. (2001), History of engine building on KPZ - Malyshev Plant 1911 - 2001 year.: history-technical sketches about engines and their developers [Istoriya dvigatelestroeniya na KhPZ - Zavode imeni Malysheva 1911 - 2001 g.g.: Istorikotekhnicheskie ocherki o dvigatelyakh i ikh sozdatelyakh ] Kharkiv: "Mitets'», GP «Zavod im. Malysheva» 480 p. 3. Ryazantsev N.K. (2009), Motors and destinies. About time and about itself: memories of the General designer on making engines for armoured vehicles [Motory $i$ sud'by. O vremeni i o sebe: Vospominaniya General'nogo konstruktora po sozdaniyu dvigatelei dlya bronetankovoi tekhniki], Kharkiv, KhNADU, 272p. 4. Alekhin S.A, Gritsyuk A.V. (2011), Anticipating time [Operedivshie vremya], Dvigateli vnutrennego sgoraniya. no 1. pp.25-28. 5. Gritsyuk A.V., Parsadanov I.V., Motora A.A.(2011), A recent trend in engine building of Ukraine [Novoe napravlenie $v$ dizelestroenii Ukrainy], Dvigateli vnutrennego sgoraniya. no 1. pp 48-53.

Поступила в редакиию 29.05.2016 г.

Грицюк Александр Васильевич-докт. техн. наук, с.н.с., заместитель генерального конструктора по НИР - главный конструктор Государственного предприятия "Харьковское конструкторское бюро по двигателестроению", Харьков, Украина, e-mail: dthkbd@ukr.net.

\section{ІСТОРІЯ СТВОРЕННЯ ЕКСПЕРИМЕНТАЛЬНОЇ БАЗИ ХАРКІВСЬКОГО КОНСТРУКТОРСЬКОГО БЮРО 3 ДВИГУНОБУДУВАННЯ \\ О.В. Грицюк}

Репрезентовано документальну інформацію з історії створення експериментальної бази цього конструкторського бюро. Показано першорядну роль випробувального устаткування експериментальної бази в забезпеченні ефективної роботи всього дослідницького напрямку КБ. Відзначено внесок кожного з керівників дослідницького напрямку в збереження і примноження науково-технічного потенціалу ХКБД. Присвячується 50-річному ювілею найменування «ХКБД».

\section{HISTORY OF CREATING OF EXPERIMENTAL BASE OF KHARKIV ENGINE DESIGN BUREAU}

\section{A.V. Gritsuk}

Documentary information on history of the creation experimental base of the design bureau is presented. The primary role of experimental base of test equipment in ensuring the efficient operation of all research unit of the design bureau is shown. Contribution of each of the heads of the research unit in preserving and increasing the scientific and technical potential KEDB is noted. Dedicated to the 50th anniversary of the name «KEDB». 